\title{
MYC Family Gene
}

National Cancer Institute

\section{Source}

National Cancer Institute. MYC Family Gene. NCI Thesaurus. Code C18537.

MYC Family Genes encode MYC Family Proteins, class III bHLH leucine zipper transcription factors having cellular proliferative and apoptotic roles. Dimerization via leucine zippers of MYC proteins with $\mathrm{bHLH} / \mathrm{lz}$ proteins, such as MAX, is required for efficient DNA binding. Leucine zippers are present in many gene regulatory proteins, including CREB proteins, Jun/AP1 transcription factors, and FOS-type proteins, as well as MYC proteins. The periodically repeated leucine side chains extending from one alpha helix interdigitate with leucine residues of another alpha helix, facilitating coiled-coil dimerization; like charge repulsion in this region perturbs homodimer formation; heterodimers are promoted by opposing charge attractions. c-MYC transcription factor binds to CAC(GA)T G DNA sites. MYC sequences have been highly conserved throughout evolution, from Drosophila to vertebrates. $(\mathrm{NCl})$ 